Published in final edited form as:

Org Lett. 2004 April 29; 6(9): 1473-1476.

\title{
A Highly Efficient Microwave-Assisted Suzuki Coupling Reaction of Aryl Perfluoro-octylsulfonates with Boronic Acids
}

\author{
Wei Zhang ${ }^{*}$, Christine Hiu-Tung Chen, Yimin Lu, and Tadamichi Nagashima \\ Fluorous Technologies, Inc. University of Pittsburgh Applied Research Center 970 William Pitt Way, \\ Pittsburgh, Pennsylvania, 15238, USA.
}

\section{Abstract}
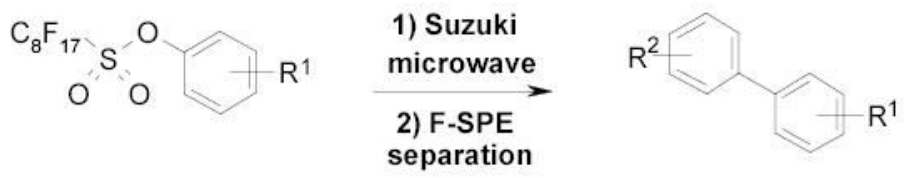

\begin{abstract}
A new strategy to improve the efficiency of Suzuki coupling reactions is introduced by combining fast microwave reaction with easy fluorous separation. Aryl perfluorooctylsulfonates derived from the corresponding phenols are coupled with aryl boronic acids to form biaryls under general microwave conditions. Both intermediates and products are purified by solid-phase extraction over FluoroFlash silica gel. Application of this tagging strategy to multistep synthesis of biaryl substituted hydantoin is also described.
\end{abstract}

The palladium-catalyzed cross-coupling of aryl halides with aryl boronic acids (Suzuki coupling) is a powerful reaction for the construction of biaryls. ${ }^{1}$ Its scope has been extended through the use of aryl triflates $\left(\mathrm{ArOSO}_{2} \mathrm{CF}_{3}\right)$ or aryl nonaflates $\left(\mathrm{ArOSO}_{2}\left(\mathrm{CF}_{2}\right)_{3} \mathrm{CF}_{3}\right)$ as halide equivalents. 2 Aryl perfluoroalkylsulfonates prepared from a wide range of commercially available phenols have shown high reactivity, good stability for room temperature storage, chromatography, and resistance towards hydrolysis. ${ }^{3}$

Application of Suzuki coupling reactions for parallel and combinatorial synthesis has been explored by conducting the reaction under microwave irradiation ${ }^{4}$ or on solid support ${ }^{5}$ with a linker such as perfluoroalkylsulfonyl. ${ }^{6}$ However, the microwave reaction does not directly address the separation issue, which is usually the bottle-neck of high-throughput synthesis. Microwave-assisted solid-phase reactions have limitations on solvent selection due to resin swelling and thermostability issues. ${ }^{7}$ We report here a new strategy which significantly improves the efficiency of Suzuki coupling reactions by combining fast microwave reaction with easy fluorous separation.

Fluorous synthesis unites the attractive features of solution-phase chemistry with the convenient workup of solid-phase chemistry. ${ }^{8}$ Molecules attached with a perfluoroalkyl "phase tag" can be easily isolated from the reaction mixture by fluorous separation techniques such as fluorous solid-phase extraction (F-SPE). ${ }^{9}$ The fluorous Suzuki coupling reaction employs aryl perfluorooctylsulfonates $\left(\mathrm{ArOSO}_{2}\left(\mathrm{CF}_{2}\right)_{7} \mathrm{CF}_{3}\right)$ as precursors. The perfluorooctylsulfonyl group has enough fluorines (17) to serve as a fluorous tag for F-SPE. Recently we reported the

w.zhang@fluorous.com.

Supporting Information Available: ${ }^{1} \mathrm{H}$ NMR spectra for aryl perfluorooctylsulfonates 1a-d, biaryls 2a-2k, compounds 4, 6, and biarylsubstituted hydantoin $\mathbf{7}$. This material is available free of charge via the internet at http://pubs.acs.org. 
use of aryl perfluorooctylsulfonate tag in palladium-mediated cross-coupling reactions for the formation of C-S bond. ${ }^{10,11}$ We now extend the application of this fluorous tag to the synthesis of C-C bond of biaryls.

A variety of phenols were converted to the corresponding aryl perfluorooctylsulfonates by reacting with commercially available perfluorooctylsulfonylfluoride under mild conditions, using $\mathrm{K}_{2} \mathrm{CO}_{3}$ as a base in dimethylformamide (DMF) at $70{ }^{\circ} \mathrm{C}$ for $5 \mathrm{~h}$ (Scheme 1). ${ }^{12}$ The crude aryl perfluorooctylsulfonate $\mathbf{1}$ has greater than $90 \%$ purity and is used directly for the next step reaction. If further purification is needed, this can be accomplished by crystallization from $\mathrm{MeOH}$ or by F-SPE purification on FluoroFlash cartridges. ${ }^{13}$ Two F-SPE fractions need to be collected; the first elution with $80: 20 \mathrm{MeOH} / \mathrm{H}_{2} \mathrm{O}$ contains unreacted phenol and other nonfluorous compounds; the second elution with $\mathrm{MeOH}$ contains the desired aryl perfluorooctylsulfonate 1. After F-SPE, the purity is greater than 95\% (Figure 1). ${ }^{14}$

Suzuki coupling is a substrate dependent reaction, which is reflected by numerous publications on the optimization of catalyst, base, solvent, and other reaction conditions. ${ }^{1,5}$ Lack of a general procedure suitable for a broad range of substrates limits the application of Suzuki reactions in high-throughput synthesis. As a powerful and easily controllable heating source, microwave irradiation can generate more consistent results than the conventional heating source. ${ }^{4}$ In our development of fluorous Suzuki coupling reactions, a literature procedure 15 for the coupling of triflates was adapted for the reaction of aryl perfluorooctylsulfonates. ${ }^{16}$ Thus, we used $\left[\mathrm{Pd}(\mathrm{dppf}) \mathrm{Cl}_{2}\right]$ (dppf = 1,1'-bis(dipenylphospanyl)ferrocene) as a catalyst, $\mathrm{K}_{2} \mathrm{CO}_{3}$ as a base, and 4:4:1 toluene/acetone $/ \mathrm{H}_{2} \mathrm{O}$ as a co-solvent. The reactions were conducted in a sealed-tube under single-mode microwave irradiation at $100-130^{\circ} \mathrm{C}$ for $10 \mathrm{~min}$. This general condition is compatible with a range of functionalized aryl perfluorooctylsulfonates such as methoxy, aldehyde, ketone, and heterocyclic groups. It is also compatible with a broad range of boronic acids including sterically hindered ortho-isopropoxy substituted boronic acid and electron-deficient 3,4-dichlorophenylboronic acid (Table 1). 17 The purification of the final product is straightforward; the organic layer of the reaction mixture was directly loaded onto a FluoroFlash SPE cartridge. The biaryl product was collected in the fraction of 80:20 MeOH/ $\mathrm{H}_{2} \mathrm{O}$, while the cleaved fluorous tag remained on the cartridge until the wash with $\mathrm{MeOH}$ was done. To avoid the other organic component to co-eluting in the $\mathrm{MeOH} / \mathrm{H}_{2} \mathrm{O}$ fraction, the boronic acid was used as the limiting agent ( $~ 0.95$ equiv.). After F-SPE, biaryl compounds were isolated in $75-95 \%$ yields with purity greater than $90 \% .{ }^{14}$ No detectable amount of dppf ligand was observed by ${ }^{1} \mathrm{H}$ NMR analysis. ${ }^{18}$

We also demonstrated the use of the fluorous sulfonyl tag in multistep synthesis of a biaryl substituted hydantoin 7 (Scheme 2). The hydroxyl group of 4-hydroxybenzaldehyde was protected by converting it to a fluorous sulfonate. The tagged benzaldehyde $\mathbf{3}$ underwent a reductive amination reaction. The resulting amine $\mathbf{4}$ was treated with an isocyanate to form urea $\mathbf{5}$, which spontaneously cyclized to form hydantoin $\mathbf{6}$. In the last step, the fluorous sulfonyl group was detagged by the Suzuki coupling reaction to form the C-C bond of biaryl 7. The efficiency of this multistep synthesis is facilitated by easy F-SPE purification of the reaction intermediates $\mathbf{4}$ and $\mathbf{6}$. The perfluorosulfonyl tag has been demonstrated to be tolerant to reductive amination and isocyanate reactions. The tagged intermediates were also found to be stable during F-SPE separations.

In this fluorous multistep synthesis, the tagging is accomplished at the phenol derivatization and the detagging at the Suzuki cross-coupling step. No synthetic steps are added just for the sake of putting in and taking off the fluorous tag. In addition to simplifying the intermediate purification, the perfluorosulfonyl group has the functions of protecting the hydroxyl group in the early steps and activating the phenol for cross-coupling at the last step. The high solubility of aryl perfluorooctylsulfonates in common organic solvents and high thermostability of the 
perfluorosulfonyl tag render the fluorous molecules good substrates for solution-phase microwave reactions. Other than formation of $\mathrm{C}-\mathrm{C}$ and $\mathrm{C}-\mathrm{S}$ bonds, the perfluorooctylsulfonate moiety is amenable to other kinds of cross-coupling reactions to form C-H, C-N, C-O, C-P, and $\mathrm{C}-\mathrm{CN}$ bonds. We believe this readily available, highly efficient, and synthetically versatile fluorous tag will have broad applications in solution-phase parallel and combinatorial syntheses.

\section{Acknowledgements}

We thank the National Institutes of General Medical Sciences for the SBIR funding (1R43GM66415-01 and 2R44GM062717-02).

\section{References}

1. a Miyaura N, Suzuki A. Chem Rev 1995;95:2457.(b) Suzuki, A. In Metal-Catalyzed Cross-Coupling Reactions; Diederich, F., Stang, P. J. Eds.; Wiley-VCH: Weinheim, Germany, 1998; Chapter 2. Stanforth, SP. , . Tetrahedron. 1998. p. 263 d Suzuki A. J Organomet Chem 1999;576:147.

2. a Stang PJ, Hanack M, Subrmanian LR. Synthesis 1982:85. b Scott WJ, McMurry JE. Acc Chem Res 1988;21:47. c Ritter K. Synthesis 1993:735. d Baraznenok IL, Nenajdenko VG, Balenkova ES. Tetrahedron 2000;56:3077.

3. Zhu J, Bigot A, Tran Huu Dau ME. Tetrahedron Lett 1997;38:1181. b Neuville L, Bigot A, Tran Huu Dau ME, Zhu J. J Org Chem 1999;64:7638. c Grushin VV. Organomettallics 2000;19:1888. d Zhang X, Sui Z. Tetrahedron Lett 2003;44:3071.

4. (a) Olofsson, K.; Hallberg, A.; Larhed, M. In Microwaves in Organic Synthesis; Loupy A. Ed. WileyVCH, Weinheim, 2002. pp 379-403.(b) Hayes, B. L. Microwave Synthesis: Chemistry at the Speed of Light; CEM Publishing: Matthews, NC, 2002. c Larhed M, Moberg C, Hallberg A. Acc Chem Res 2002;35:717. [PubMed: 12234201]

5. Selected papers: (a) LiWBurgessKTetrahedron Lett1999406527 b Brase S, Schroen M. Angew Chem Int Ed 1999;38:1071. c Vanier Y, Lorge F, Wagner A, Mioskowski C. Angew Chem Int Ed 2000;39:1679. d Pourbaix C, Carreaux F, Carboni B. Org Lett 2001;3:803. [PubMed: 11263886] e Yamada YMA, Takeda K, Takahashi H, Ikegami. Org Lett 2002;4:3371. [PubMed: 12323021] f Lan P, Berta D, Porco JA, South MS, Parlow JJ. J Org Chem 2003;68:9678. [PubMed: 14656094] g Organ MG, Mayer S. J Comb Chem 2003;5:118. [PubMed: 12625701] h Wade JV, Krueger CA. J Comb Chem 2003;5:267. [PubMed: 12739943] i Zhu S, Shi S, Gerritz SW, Sofia MJ. J Comb Chem 2003;5:205. [PubMed: 12739932] j Byun JW, Lee YS. Tetrahedron Lett 2004;45:1837.See also general reviews: (k) Negishi, E.; Ed. Hankbook of Palladium Chemistry; Wiley: New York, 2002. 1 Lorsbury BA, Kurt MJ. Chem Rev 1999;99:1549. [PubMed: 11849002] m Brase S, Kirchhoff JH, Kobberling J. Tetrahedron 2003;59:885.

6. a Pan Y, Ruhland B, Holmes CP. Angew Chem Int Ed 2001;40:2288. b Pan Y, Holmes CP. Org Lett 2001;3:2769. [PubMed: 11506630]

7. a Larhed M, Lindeberg G, Hallberg A. Tetrahedron Lett 1996;37:8219.(b) Kappe, O. C.; Stadler, A. In Microwaves in Organic Synthesis; Loupy A. Ed. Wiley-VCH, Weinheim, 2002. pp 405-433.

8. Recent reviews: (a) CurranDPAngew Chem, Int Ed Eng1998371175(b) Curran, D. P. In Stimulating Concepts in Chemistry; F. Stoddard, D. Reinhoudt and M. Shibasaki, Ed.; Wiley-VCH: New York, 2000; pp 25-37.(c) Curran, D. P.; Hadida, S.; Studer, A.; He, M. ; Kim, S.-Y.; Luo, Z.; Larhed, M.; Hallberg, A.; Linclau, B. In Combinatorial Chemistry: A Practical Approach; Fenniri, H. Ed.; Oxford Univ. Press: Oxford, 2000; Vol. 2; pp 327-352. d Dobbs AP, Kimberley MR. J Fluorine Chem 2002;118:3. e Zhang W. Tetrahedron 2003;59:4475.

9. a Curran DP. Synlett 2001:1488. b Yoshida J, Itami K. Chem Rev 2002;102:3693. [PubMed: 12371899] c Tzschucke CC, Markert C, Bannwarth W, Roller S, Hebel A, Haag R. Angew Chem Int Ed 2002;41:3964.

10. Zhang W, Lu Y, Chen CHT. Mol Diversity 2003;7:199.

11. For early work on microwave-assisted cross-coupling reactions and fluorous liquid-liquid separations, see: (a) LarhedMHoshinoMHadidaSCurranDPHallbergAJ Org Chem1997625583 b Olofsson K, Kim SY, Larhed M, Curran DP, Hallberg A. J Org Chem 1999;64:4539. 
12. A representative procedure for the preparation of aryl perfluoro-octylsulfonates: To a mixture of 5hydroxy-1-teralone $(3.24 \mathrm{~g}, 20.0 \mathrm{mmol})$ and $\mathrm{K}_{2} \mathrm{CO}_{3}(2.90 \mathrm{~g}, 21.0 \mathrm{mmol})$ in $15 \mathrm{ml}$ of DMF was added perfluorooctylsulfonic fluoride $(8.37 \mathrm{~g}, 16.7 \mathrm{mmol})$ dropwise through an addition funnel. After heating at $70^{\circ} \mathrm{C}$ for $5 \mathrm{~h}$, the mixture was poured onto $100 \mathrm{ml}$ of water and extracted with EtOAc. The organic portions was dried over $\mathrm{MgSO}_{4}$, the solvent was evaporated under vacuum to give perfluorooctylsulfonate $1 \mathrm{a}(9.79 \mathrm{~g}, 91 \%$ yield). The crude product was used for the next step. It can be further purified by recrystallization with $\mathrm{MeOH}$ or by F-SPE.

13. FluoroFlash silica gel charged in the $\mathrm{SPE}$ cartridges contains a $\mathrm{Si}(\mathrm{Me})_{2} \mathrm{C}_{8} \mathrm{~F}_{17}$ stationary phase. For more information about F-SPE, please log on to: http://www.fluorous.com/download/fspe.pdf

14. Purities were assessed by ${ }^{1} \mathrm{H}$ NMR.

15. Pridgen LN, Huang GK. Tetrahedron Lett 1998;39:8421.

16. A representative procedure for the Suzuki cross-coupling reaction: A septum-sealed microwave tube charged with aryl perfluoroctylsulfonate $1 \mathrm{a}(84.0 \mathrm{mg}, 0.13 \mathrm{mmol}), 4$-methoxyboronic acid $(18.9 \mathrm{mg}$, $0.12 \mathrm{mmol}$ ), $\mathrm{Pd}$ (pddf)Cl 2 (10.6 mg, $0.013 \mathrm{mmol}), \mathrm{K}_{2} \mathrm{CO}_{3}(36.0 \mathrm{mg}, 0.26 \mathrm{mmol})$ in $0.8 \mathrm{~mL}$ of 4:4:1 acetone/toluene $/ \mathrm{H}_{2} \mathrm{O}$ co-solvent was irradiated in a monomode microwave cavity $\left(150 \mathrm{w}, 130{ }^{\circ} \mathrm{C}, 10\right.$ $\mathrm{min})$. The reaction mixture was washed with $1 \mathrm{~mL}$ of $\mathrm{H}_{2} \mathrm{O}$. The organic layer was loaded onto a $5 \mathrm{~g}$ FluoroFlash cartridge pre-conditioned with $80: 20 \mathrm{MeOH} / \mathrm{H}_{2} \mathrm{O}$. The cartridge was eluted with $10 \mathrm{~mL}$ of $80: 20 \mathrm{MeOH} / \mathrm{H}_{2} \mathrm{O}$. The fraction was concentrated to give biaryl $2 \mathrm{a}(27.6 \mathrm{mg}, 91 \%$ yield). The fluorous species were washed out from the cartridge with $20 \mathrm{~mL}$ of $\mathrm{MeOH}$.

17. Pd-catalyzed microwave reactions were conducted under a license form Personal Chemistry.

18. No further quantitative analysis has been attempted to detect the residue of catalyst and ligand in final products. 


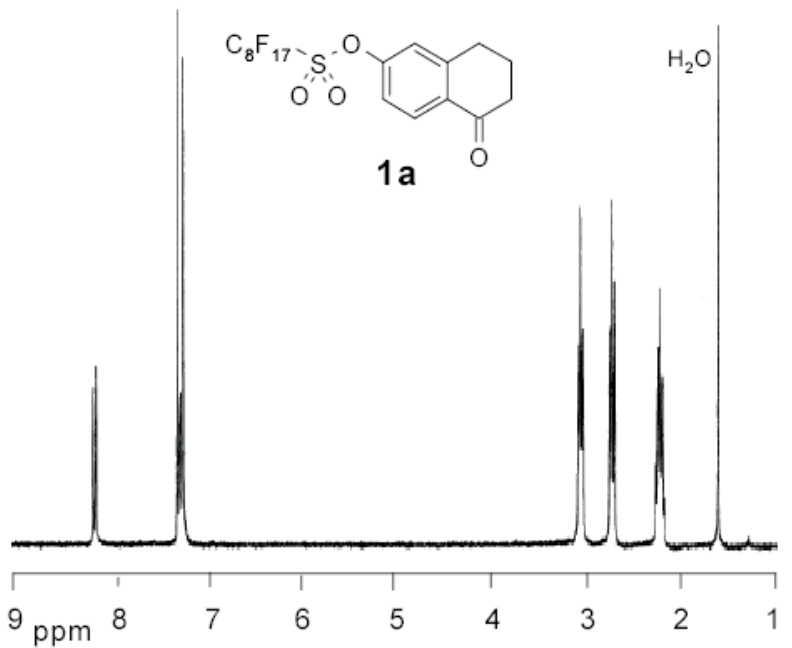

Figure 1.

${ }^{1} \mathrm{H} \mathrm{NMR}\left(\mathrm{CDCl}_{3}\right)$ of $\mathbf{1 a}$ after F-SPE 


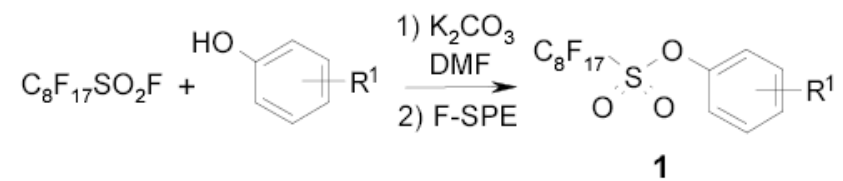

1) $\mathrm{R}^{2} \mathrm{PhB}(\mathrm{OH})_{2}$
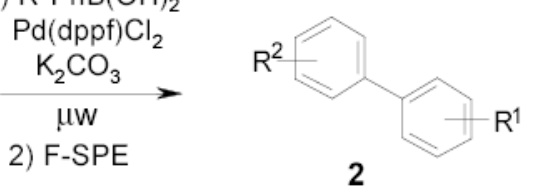

Scheme 1.

Fluorous Synthesis of Biaryls 

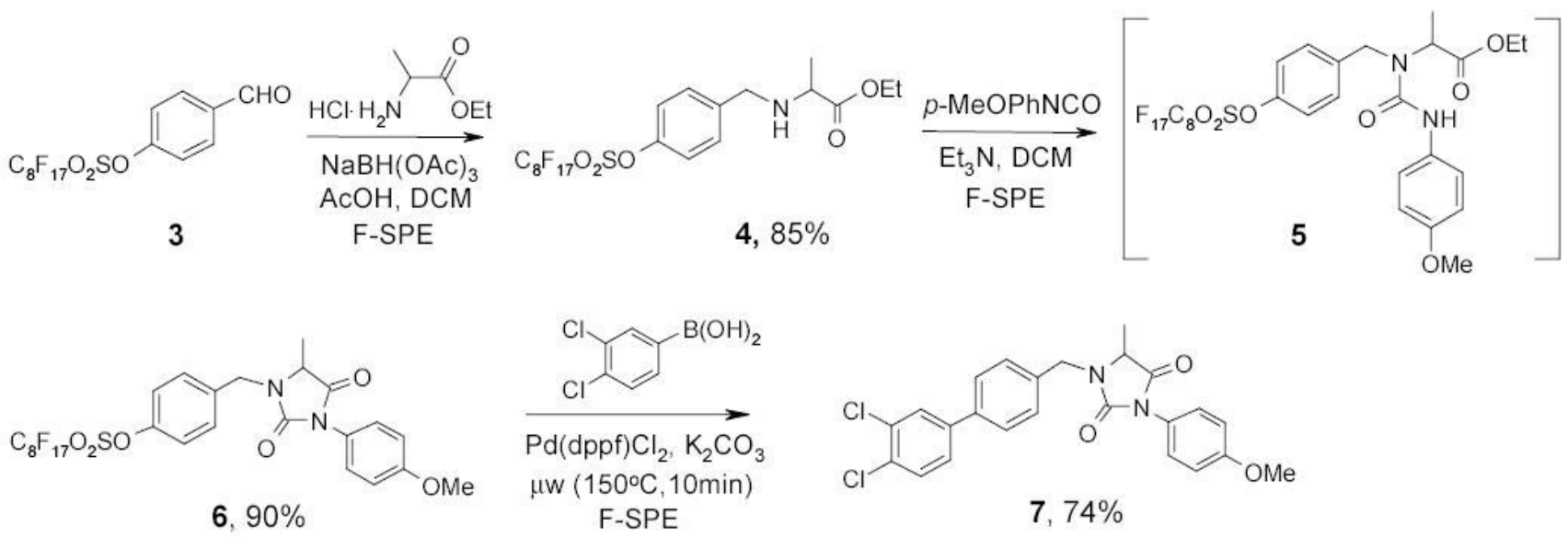

Scheme 2.

Fluorous Synthesis of Biaryl-Substituted Hydantoin 7 


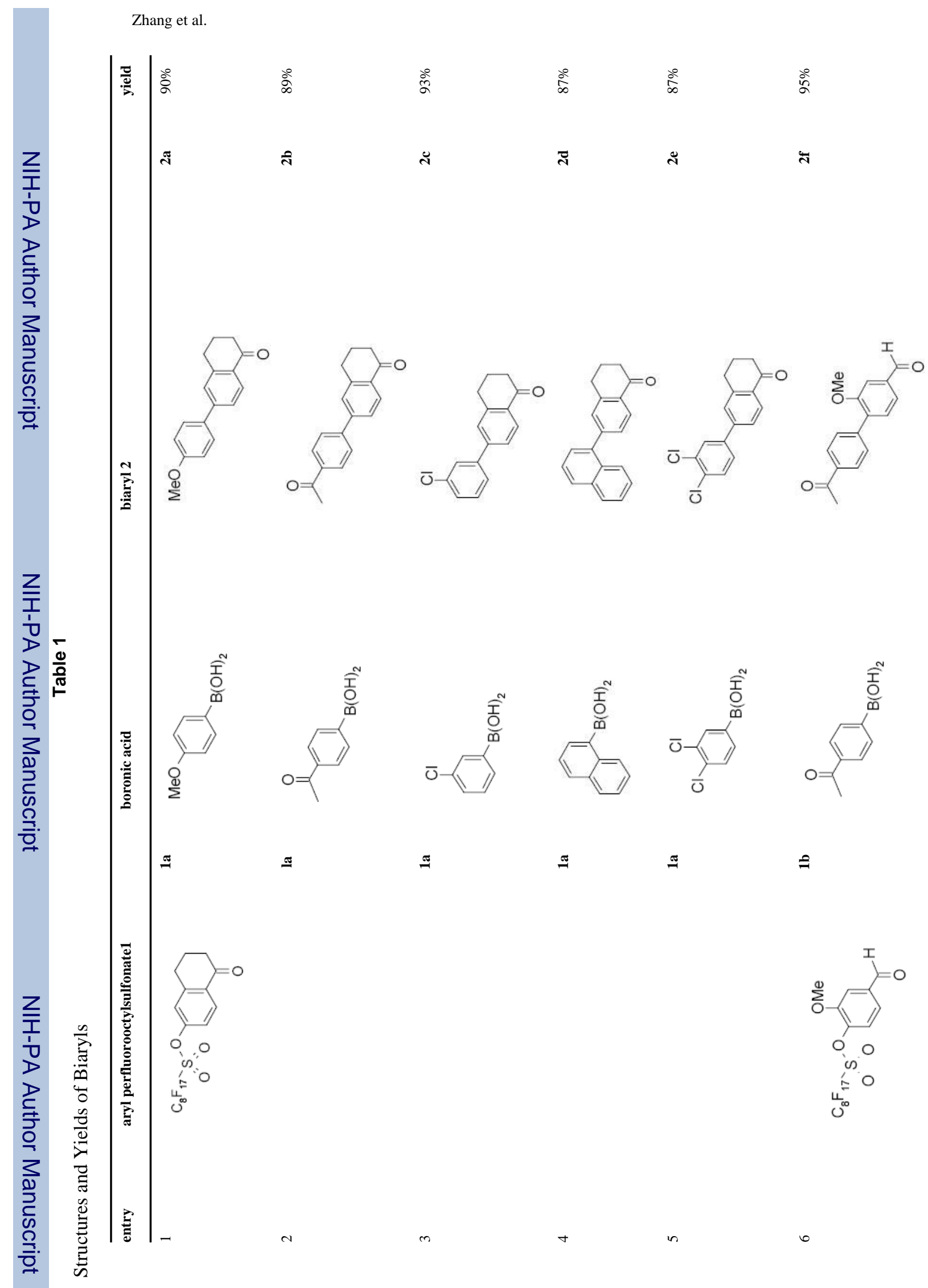

Org Lett. Author manuscript; available in PMC 2006 October 23. 


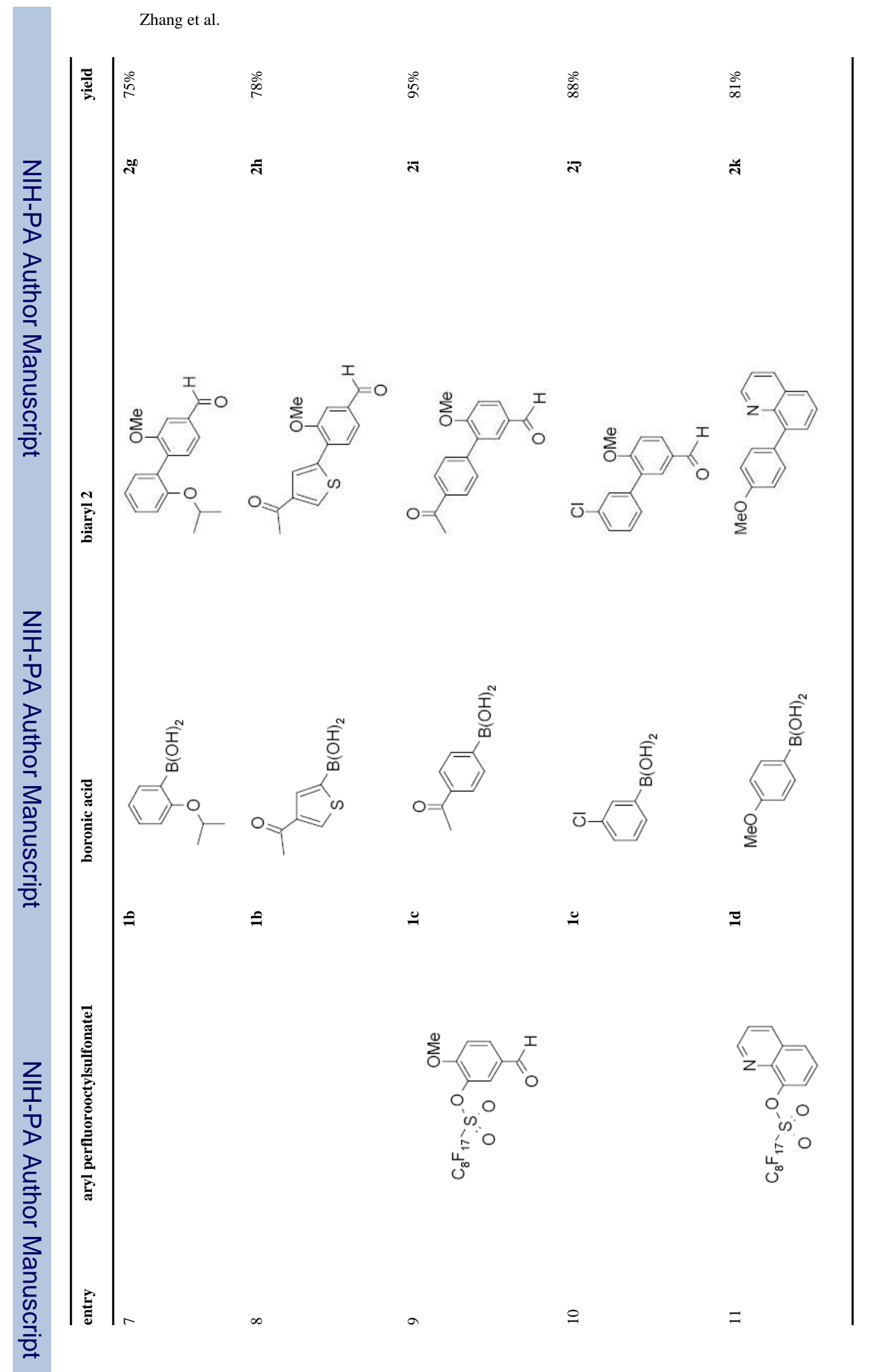

Page 9 